\title{
Legitimacy in Multistakeholder Global Governance at ICANN
}

\author{
Hortense Jongen | ORCID: 0000-0002-4170-9898 \\ Department of Political Science and Public Administration, \\ Vrije Universiteit Amsterdam, Amsterdam, The Netherlands \\ h.j.e.m.jongen@vu.nl
}

\author{
Jan Aart Scholte | ORCID: 0000-0001-8434-588X \\ Institute of Political Science, and Institute of Security and Global Affairs, \\ Leiden University, The Netherlands \\ scholteja@vuw.leidenuniv.nl
}

\begin{abstract}
This article examines levels and patterns of legitimacy beliefs toward one of today's most developed global multistakeholder regimes, the Internet Corporation for Assigned Names and Numbers (ICANN). Two complementary surveys find that levels of legitimacy perceptions toward ICANN often rank alongside, and sometimes ahead of, those for other sites of global governance, both multilateral and multistakeholder. Moreover, average legitimacy beliefs toward ICANN hold consistently across stakeholder sectors, geographical regions, and social groups. However, legitimacy beliefs decline as one moves away from the core of the regime, and many elites remain unaware of ICANN. Furthermore, many participants in Internet governance express only moderate (and sometimes low) confidence in ICANN. To this extent, the regime's legitimacy is more fragile. Extrapolation from mixed evidence around ICANN suggests that, while multistakeholder global governance is not under existential threat, its legitimacy remains somewhat tenuous.
\end{abstract}

\section{Keywords}

global governance - ICANN - legitimacy - multilateralism - multistakeholderism 
In contrast to multilateral global governance, which reserves decision-taking only for states, multistakeholder arrangements also give nonstate actors authority in global policy processes. ${ }^{2}$ These nonstate parties can include business, civil society, researchers, technicians, and the public at large. Indeed, some multistakeholder frameworks deliberately sideline the state.

Immediately, the question of legitimacy arises: Is it appropriate for private agents to make public policy in global affairs? Proponents of multistakeholder approaches affirm that convening representatives of different affected groups in joint policymaking is a relevant, informed, creative, swift, responsive, adaptable, participatory way of global governing. ${ }^{3}$ Champions of multistakeholderism often assert further that this alternative is more democratic, effective, and fair than traditional intergovernmentalism. In contrast, opponents argue that multistakeholder global governance is liable to amateurism, confusion, inefficiency, poor compliance, special-interest capture, and unaccountability. ${ }^{4}$ The critics often call for greater state oversight of multistakeholder institutions, or even a reversion to conventional multilateralism. As these claims and counterclaims indicate, the legitimacy of multistakeholder global governance is much in question.

1 The authors give major thanks to Alexandra Bousiou and Evie Papada for their inputs to constructing the ICANN survey questionnaire and for between them conducting around 40 percent of the interviews. We further thank student interns Elvina Borombaeva, Natalie Dinham, Linn Lundquist, Aaron Mannis, and Maria Verkhovtseva for assistance with various survey preparations. Principal research for this paper was carried out within the project "Legitimacy outside the State: Governing the Global Internet," with funding from the Swedish Research Council (Grant no. 2017-03076_3). In addition, Jan Aart Scholte together with Lisa Dellmuth, Jonas Tallberg, and Soetkin Verhaegen conducted supplementary research on elite attitudes toward global governance through the program "Legitimacy in Global Governance" (LegGov), with funding from Riksbankens Jubileumsfond (Grant no. M15-0048:1). The authors in particular thank Soetkin Verhaegen for preparing and sharing data analysis from the LegGov elite survey. For feedback on earlier versions of this article, the authors thank colleagues in the full LegGov program; seminars at Carleton University and McGill University; a dozen ICANN constituency groups; audiences at the 6oth Annual Convention of the International Studies Association, the Third European Multidisciplinary Conference on Global Internet Governance, and the 13th Pan-European Conference on International Relations; and reviewers for Global Governance.

2 Kurbalija and Katrandjiev 2006; Hallström and Boström 2010; Raymond and DeNardis 2015; Gleckman 2018.

3 Cf. Khagram 2006; Abbott and Snidal 20o9; Waddell 2011; Tapscott 2014.

4 Cf. Ottaway 2001; Black 2008; Hofmann 2016; Gleckman 2018. 
Yet what do affected people themselves think about legitimacy with respect to global multistakeholder institutions? After several decades of increased use across many issue areas, what levels of legitimacy beliefs do these arrangements attract? How many people, across which constituencies, and with what degrees of conviction endorse the authority of global multistakeholder regimes? Answers to these questions can provide important clues about future trends in global governance. ${ }^{5}$ Strong legitimacy beliefs could help global multistakeholder frameworks to thrive, spread, and perhaps even overtake old-style multilateralism. Conversely, weak and absent legitimacy beliefs could undermine global multistakeholder apparatuses and encourage turns to intergovernmentalism or other institutional formats.

Until now, the absence of solid data has made it difficult to assess legitimacy perceptions toward multistakeholder global governance. Some important work has addressed general conceptual aspects of the question, ${ }^{6}$ and several studies have examined legitimacy in relation to a particular global multistakeholder apparatus. ${ }^{7}$ Yet, with one exception, ${ }^{8}$ we lack systematic large- $N$ data about legitimacy beliefs in multistakeholder global governance.

This article addresses this gap with evidence regarding the Internet Corporation for Assigned Names and Numbers (ICANN). ${ }^{9}$ Established in 1998, ICANN oversees rules for, and coordination of, the domain name system (DNS) as a unified addressing scheme for the global internet. ICANN also administers operationalization of two other so-called IANA (Internet Assigned Numbers Authority) functions: namely, the allocation of Internet Protocol (IP) numbers and the implementation of protocol parameters (i.e., software standards that enable data transmission across the global internet). In short, without ICANN (or some other body that accomplished its purpose), there would be no internet as we know it.

ICANN is a multistakeholder apparatus. Commercial voices speak at ICANN through the (domain name) Registries Stakeholder Group, the (domain name) Registrar Stakeholder Group, the Business Constituency, the Intellectual Property Constituency, and the Internet Service Providers and Connectivity Providers Constituency. Technical experts engage with ICANN through the Address Supporting Organization, the Root Server System Advisory Com-

5 Mayntz 2010; Sommerer and Agné 2018.

6 Cashore 2002; Bernstein and Cashore 2007; Quack 2010; Bernstein 2011; Curtin and Senden 2011.

7 Dingwerth 2007; Marx 2014; Hahn and Weidtman 2016.

8 Nasiritousi and Verhaegen 2020.

9 Antonova 2008; Flyverbom 2011; Mahler 2019. 
mittee, and the Security and Stability Advisory Committee. Civil society and academic inputs to ICANN come chiefly through the Non-Commercial Stakeholders Group. Individual internet users become involved in ICANN through At-Large Structures. States participate in ICANN through the Government Advisory Committee. The Country Code Names Supporting Organizationwhich considers global policies on country strings such as ".cn" and ".uk"combines academic, commercial, governmental, and civil society elements. Taken together, these constituency organizations are known at ICANN as "the community." The various community groups have seats on the ICANN Board of Directors. Policy execution occurs through the staff (so-called ICANN org), with headquarters in Los Angeles and eight other offices around the world.

ICANN is a particularly apt setting to examine legitimacy beliefs in global multistakeholder governance. First, the authority is important: ICANN is a striking instance where a multistakeholder apparatus manages a critical global resource: i.e., today's worldwide digital communications network. Second, ICANN is a large operation: its multistakeholder processes have involved thousands of participants, and staff numbered 386 as of April 2020. Third, ICANN has given meticulous attention to developing multistakeholder arrangements, with continual organizational reviews and revisions. ${ }^{10}$ In particular, the socalled IANA stewardship transition of 2014-2016 saw herculean efforts for the legitimation of a fully privatized ICANN. ${ }^{11}$ Fourth, ICANN's multistakeholder approach has often stood in overt competition with multilateralism, especially through the United Nations. ${ }^{12}$ Fifth, ICANN has concertedly promoted the multistakeholder model and styled itself as an example for others to follow. In the words of one leading figure, "Quite a lot of ICANN's energy, money, time, focus and so forth has been spent at selling the idea of ICANN."13 Sixth, ICANN has long had a major explicit preoccupation with its legitimacy. ${ }^{14}$ Indeed, at the close of ICANN's latest constitutional reconstruction in 2016, the lead US official in the process declared, "The legitimacy point is perhaps the most critical component as we think about extending the multistakeholder process." ${ }^{15}$

So, after twenty years of intensive efforts, how far do people today regard ICANN as legitimate? How much confidence do various constituencies give

\footnotetext{
$10 \quad$ Palfrey 2004; Koppell 2005; Mueller 2010.

11 Becker 2019.

12 Kleinwächter 2004; Mueller 2010.

13 Interview, 21 December 2018.

14 Weinberg 2000; Mounier 2012.

15 Strickling 2016.
} 
this multistakeholder apparatus? Does ICANN have firm foundations of legitimacy beliefs, as could potentially enhance its mandate, resources, compliance, problem-solving impacts, and standing against potential competitor institutions ${ }^{16}$ Or, on the contrary, does multistakeholder governance of the internet through ICANN face low and fragile legitimacy beliefs, making it vulnerable to rival institutional designs?

To assess this issue, we have undertaken an empirical study (unprecedented in its scale and detail) of legitimacy perceptions toward global multistakeholder governance at ICANN. ${ }^{17}$ In 2018-2019 we interviewed a random sample of 529 participants in global internet governance about their assessments of the ICANN regime. A parallel survey asked a targeted sample of 86o general elites around the world (i.e., political and societal leaders who are not involved in internet policy) about their assessments of ICANN and a range of other global governance institutions. The research did not collect data on general public opinion, given low levels of awareness of ICANN among citizens at large.

This article presents the results regarding levels and patterns of legitimacy perceptions vis-à-vis ICANN. Section 2 has a conceptual focus and discusses: (a) legitimacy as a crucial issue for any form of (global) governance; and (b) the various constituencies of a regime and how legitimacy perceptions might vary between them. Section 3 has a methodological focus and describes the two surveys. Section 4 then presents empirical results, examining levels of "confidence" (as a proxy for legitimacy) toward ICANN. We consider the data both in aggregate and as broken down by stakeholder sectors, by world regions, and by social groups.

Overall, the findings show mixed results. On the one hand, legitimacy beliefs toward ICANN hold consistently across stakeholder, regional, and social groups. To this extent, two decades of legitimation efforts have borne fruit. On the other hand, many both inside and outside ICANN report moderate or even low confidence in the regime, while the general public is largely ignorant of ICANN and so has no legitimacy views at all. To this extent, legitimacy for multistakeholder governance at ICANN has fragile aspects.

16 Sommerer and Agné 2018.

17 Another empirical study, Take 2012, involves a narrower approach and a smaller evidence base. 


\section{Conceptual Notes}

This article offers a descriptive and interpretive account rather than explanatory and causal analysis. We explore in detail levels and patterns of legitimacy, an approach that allows us to reflect on the contextual circumstances of different audiences. Of course, this descriptive analysis has conceptual underpinnings that require specification, particularly around the notion of legitimacy. This section also considers what patterns of legitimacy beliefs we anticipate, before seeing whether the survey data confirm such expectations.

Legitimacy, as understood here, entails the belief and perception that a governor has a right to rule and exercises it appropriately. ${ }^{18}$ When subjects regard a regime as legitimate, they accord it confidence and trust. As such, legitimacy involves underlying approval of a governing apparatus, as distinct from contingent support based on particular rulers or specific policies. ${ }^{19}$ When people view a regime as legitimate, they will be inclined to follow its rules even if they oppose the current leadership and even if certain measures operate against their immediate interests. Thus, legitimacy can greatly boost governing power: the more a regulatory apparatus has legitimacy, the less it needs to invoke coercion, trickery, and secrecy to sustain itself.

Modern political theory has explored legitimacy mainly in relation to the state.$^{20}$ However, the growth of regional and global regulation in recent times has prompted increased attention to legitimacy beyond the national sphere. ${ }^{21}$ We need to examine legitimacy, as a core attribute of power, wherever there is authoritative rule. As governance spreads beyond the state to other quarters, including multistakeholder global regimes, research on legitimacy must adjust accordingly. Yet, as previously noted, empirical work on legitimacy in multistakeholder global governance is lacking.

As implied already, the present study addresses legitimacy in sociological rather than normative terms. ${ }^{22}$ Our aim is not to develop philosophical arguments about whether people should regard ICANN as legitimate. Rather, we explore how far ICANN's subjects do believe this multistakeholder regime is legitimate. Of course, the normative dispositions of researchers affect, whether consciously or not, their collection and interpretation of empirical evidence.

\footnotetext{
18 Weber [1922] 1978; Suchman 1995.

19 Easton 1975.

20 Parsons 196o; Habermas [1973] 1976; Barker 199o; Beetham 2013.

21 Zaum 2013; Zürn 2018; Tallberg, Bäckstrand, and Scholte 2018; Dingwerth et al. 2019.

22 Weber [1922] 1978; Norris 2009; Ecker-Ehrhardt 2016; Zürn 2018; Tallberg, Bäckstrand, and Scholte 2018.
} 
Still, the concern here is to identify and measure the legitimacy beliefs of others, and not to discover and defend our own values in the matter.

Legitimacy beliefs are held by what the literature variously terms "the governed," "subjects," "constituencies," or "audiences."23 Earlier research assumes that states are the only relevant holders of legitimacy perceptions in world politics. Nowadays, with growing (acknowledgment of) transnational alongside international relations, research on legitimacy in global governance increasingly examines nongovernmental as well as governmental constituencies. Certainly with respect to multistakeholder regimes - where states generally play a secondary role - a wider concept of audiences is required.

It is important to distinguish different groups of the governed. After all, different types of subjects can have very different relationships with a regime. These varying positions can, in turn, correspond with stronger or weaker legitimacy perceptions. The question is always legitimacy in whose eyes.

Our study of ICANN distinguishes six types of subjects: three of them "outsiders" and three of them "insiders." The outsiders are recipients of ICANN's rules. The insiders make the ICANN regime function. One can conceive of the six constituencies in funnel fashion, starting with the largest circle of outsiders (the general public) and ending with the narrowest circle of decision-takers (the ICANN board).

Regarding outsiders, our data collection excludes the general public, given that most citizens, although governed by ICANN's rules, seem unaware of the regime. However, we do present evidence regarding general elites, the second outsider constituency, since we expect political and societal leaders to know of global governance institutions such as ICANN. Indeed, around half of surveyed elites around the world express an opinion about ICANN. A third constituency comprises informed outsiders; namely, persons who are active in global internet governance, but do not participate in ICANN deliberations.

Among ICANN's three insider constituencies, the largest is "the community" of persons who actively participate in the regime's policy development processes. A second insider constituency is ICANN staff, whose level of confidence in the regime could deeply shape the formulation and implementation of multistakeholder policies. A third insider group is the board of directors, the core decision-takers in the ICANN regime.

Theoretically, we would expect legitimacy beliefs to vary across ICANN's constituencies. For example, we might anticipate that legitimacy perceptions would be stronger the closer a person is to the heart of the ICANN regime.

23 Bexell and Jönsson 2018. 
On this assumption, legitimacy beliefs would range from highest for the board and staff to lowest for the general public. We might also predict that legitimacy beliefs would be higher among people who are generally regarded to have more influence and gain at ICANN. Thus, in terms of stakeholder groups, we might expect that legitimacy beliefs would be higher among business constituencies, given their large power in and benefits from ICANN, and lower among governments, given their general marginalization in ICANN's multistakeholder framework. In terms of regional groups, we might predict higher legitimacy perceptions from Europe and North America, given their predominant presence at ICANN, and lower legitimacy views from other world regions. Among social categories, we might expect lower evaluations of legitimacy from women, younger people, non-English speakers, and people of color, given their minority positions in the ICANN regime. As we see in Section 4, the survey evidence corroborates some of these expectations, but also confounds others.

\section{Methodological Notes}

Our data on legitimacy beliefs toward ICANN come from two surveys. Evidence regarding the three insider constituencies and the "informed outsiders" derives from survey interviews conducted between October 2018 and July 2019 with 529 participants in global internet governance. Evidence regarding the legitimacy perceptions toward ICANN of general elites comes from another survey undertaken between October 2017 and August 2019 with 86o respondents in sample countries across six world regions. We conducted the ICANN survey ourselves, while the general elite survey was done together with the Legitimacy in Global Governance (LegGov) project. ${ }^{24}$ We have judged that the general population is too little aware of ICANN to warrant a further public opinion survey for this study.

Regarding ICANN insiders, we invited for interview all 30 ICANN board members from the period 2015-2018, plus 182 ICANN staff members and a random sample of 741 ICANN community participants. We interviewed all 30 board members (response rate 100 percent), 132 staff members (response rate 72.5 percent), and 305 community participants (response rate 41.2 percent). In total, then, we conducted 467 insider interviews with an overall response rate of 49.0 percent. The sample of ICANN community interviewees is broadly

24 Additional information about the sampling procedure, interview process, and distribution of responses for this survey can be found in Verhaegen et al. 2019. 
representative, covering all stakeholder sectors, all geographic regions, and all social groups - and in proportions that largely reflect patterns of involvement in ICANN meetings (according to published attendance statistics).

Concerning the "outsider" populations, we contacted 180 informed outsiders and interviewed 62 , for a response rate of 34.4 percent. Our aim with this group was less to obtain a full picture of external perceptions of ICANN, but more to check how far informed outsider views might deviate from insider attitudes. ${ }^{25}$

The general elite survey covered a targeted sample of 860 people who hold leading positions in key organizations in society that strive to be politically influential. The respondents were spread evenly across Brazil, Germany, the Philippines, Russia, South Africa, and the United States, plus a global group of leaders in international and transnational organizations. We thereby tapped into diverse cultural, economic, ideological, political, and regional contexts worldwide. ${ }^{26}$ Each geographical subsample was divided half-and-half between "political" elites (in turn split evenly between government bureaucracy and political parties) and "societal" elites (in turn evenly distributed between business, civil society, media, and research circles). The overall response rate for the general elite survey was 31.8 percent.

In conformity with other research on legitimacy in global governance, the two surveys adopt a common political science practice of operationalizing legitimacy in terms of "confidence," which has advantages as detailed elsewhere. ${ }^{27}$ Respondents to the ICANN survey were asked, "How much confidence do you have in the current workings of ICANN overall?" Answer options were: o (very low), 1 (low), 2 (moderate), 3 (high), and 4 (very high). In addition, we solicited respondents' confidence in other key actors in internet governance: the Internet Engineering Task Force (IETF), the Internet Governance Forum (IGF), the International Telecommunication Union (ITU), their Regional Internet Registry (RIR), and their national government. The general elite survey asked respondents to indicate their level of confidence in ICANN, alongside thirteen other global governance institutions. Answer options were:

25 Details about the sampling procedure, the interviewing process, and the distribution of respondents in the ICANN survey can be found in Jongen and Scholte (2021).

26 The selection within this diversity (e.g., Brazil rather than Argentina, Germany rather than France, Russia rather than China, South Africa rather than Nigeria) was largely determined by our capacity to tap local professional networks to help execute the survey. Specific country choices could, of course, affect results at the margins, but our sample covers the main economic, geopolitical, and ideological cleavages in internet governance.

27 Norris 2009; Voeten 2013; Dellmuth and Tallberg, 2015; Dellmuth, Scholte, and Tallberg 2019 . 
o (no confidence at all), 1 (not very much confidence), 2 (quite a lot of confidence), and 3 (a great deal of confidence). ${ }^{28}$

The data analysis elaborated in Section 4 describes patterns in legitimacy toward ICANN. We complement the descriptive statistics with independent samples $t$-tests, which help to identify statistically significant differences between two groups. We have weighted the data to counter an overrepresentation of board and staff among the interviewed insiders, so that their impact on the aggregate ICANN insider scores reflects their share in the overall insider population. ${ }^{29}$ The imbalances result from our decision to do a full census for the board and staff, in order to obtain representative results for each of these groups in their own right.

\section{Data Analysis}

What levels and variations of legitimacy beliefs toward ICANN do these surveys reveal? After two preliminary observations, we examine in detail the legitimacy beliefs of general elites. Then, we look more specifically at participants in internet governance and compare confidence levels for ICANN with that for other institutions. Thereafter, we dissect confidence levels for ICANN itself by stakeholder sector, geographical region, and social group.

A first preliminary observation is that respondents in our ICANN survey overwhelmingly confirmed the theoretical expectation that legitimacy matters for multistakeholder global governance. No less than 96.6 percent of respondents affirmed that legitimacy is either "extremely important" (79.5 percent) or "quite important" (17.1 percent) for ICANN. Elaborating on these answers, respondents typically asserted that, without legitimacy, participation in ICANN would decline, other institutions would take over ICANN's role, the global internet could fragment, and general chaos would ensue in global digital communications.

A second preliminary observation is that an absence of awareness of ICANN among the public at large leaves the regime with a narrow base of legitimacy. True, the world's 4.7 billion regular internet users (as of 2020) obtain notional representation in the ICANN multistakeholder framework through

28 Since the two surveys were conducted in different research projects, they have different response scales. Still, both surveys tap into the same issue: confidence in global governance institutions.

29 The weightings are 0.317 for the board, 0.451 for the staff, and 1.305 for the community. 


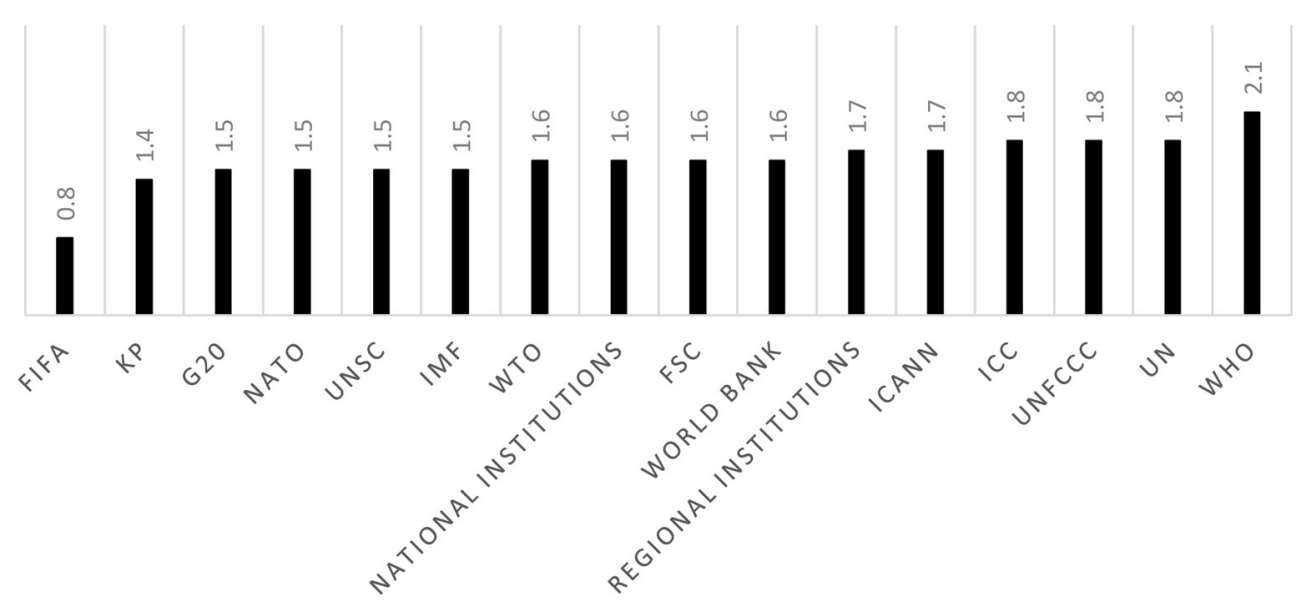

FIGURE 1 Confidence in global governance institutions among world elites (means, o-3 scale) Regional governance institutions are Mercado Comun do Sul (MERCOSUL) for Brazil, European Union (EU) for Germany, Association of Southeast Asian Nations (ASEAN) for the Philippines, Shanghai Cooperation Organization (SCO) for Russia, African Union (AU) for South Africa, and North American Free Trade Agreement/United States-Mexico-Canada Agreement (NAFTA/USMCA) for the United States of America. National institutions included are the government and parliament.

VERHAEGEN ET AL. (2O19)

the At-Large Constituency. However, participants in At-Large are self-selected and have few systematic communications with the wider public..$^{30}$

\subsection{ICANN in Comparison with Other Global Governance Institutions}

Starting with a wider picture, we sought views on ICANN from general elites around the world and situated these assessments among a range of other global governance institutions. We find that, for this audience, ICANN attracts an overall moderate level of confidence of 1.7 , somewhat above the midway point on the scale of o to 3 (Figure 1 ). Thus, general elites on average lean more toward "quite a lot of confidence" in ICANN than "not very much confidence." Still, the overall evaluation might be characterized as lukewarm rather than enthusiastic. Moreover, 49.7 percent of respondents in the elite survey replied "I do not know" or did not answer this question, raising further issues about the breadth of ICANN's legitimacy base.

Those general elites who know of ICANN rank it fifth in confidence among fourteen global governance institutions. Notably, ICANN as a multistakeholder arrangement comes just ahead of multilateral economic institutions such as 


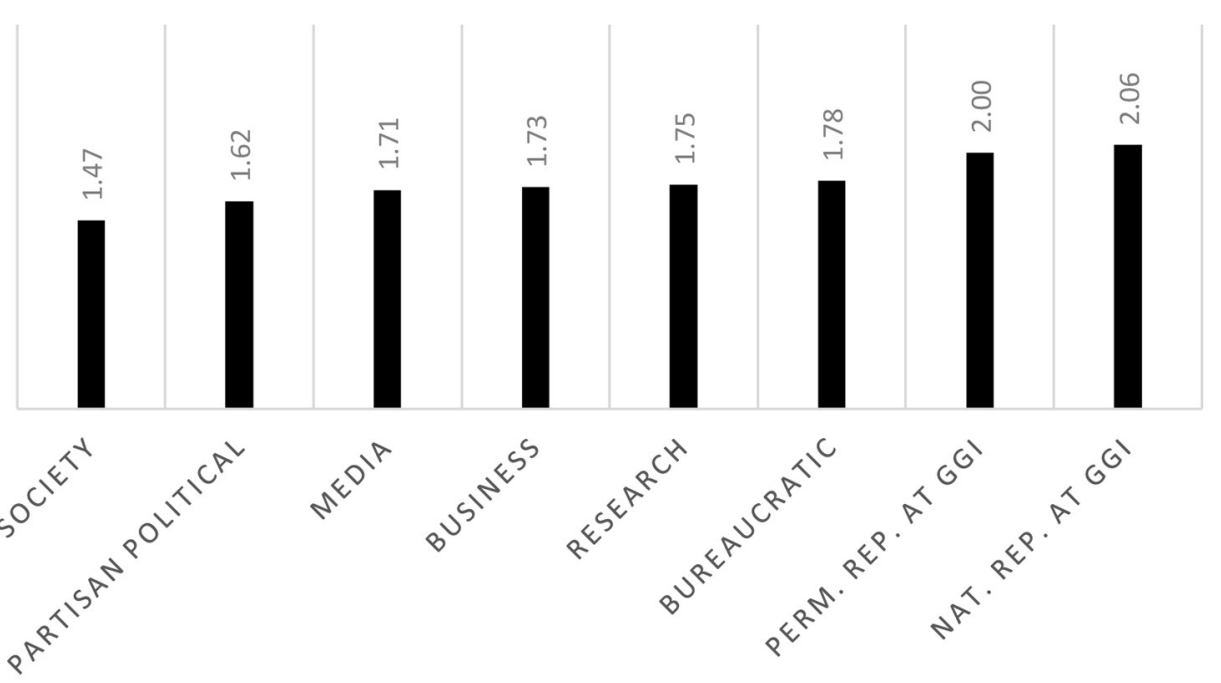

FIGURE 2 Confidence in the Internet Corporation for Assigned Names and Numbers (ICANN) across stakeholder groups (elites; means, o-3 scale; $N=432$ )

DATA FROM VERHAEGEN ET AL. (2O19)

the World Bank and the World Trade Organization (WTO), and only just behind the International Criminal Court (ICC), the United Nations Framework Convention on Climate Change (UNFCCC), and the UN more generally. In addition, elites' confidence in ICANN comes well ahead of the intergovernmental International Monetary Fund (IMF), the transgovernmental Group of 20 (G20), and the private International Association of Federation Football (FIFA). ICANN also returns the highest score of the three multistakeholder regimes in the elite survey, ahead of the Kimberley Process (KP) at 1.4 and the Forest Stewardship Council (FSC) at 1.6. ICANN has a substantially lower confidence score only relative to the World Health Organization (WHO).

Disaggregating headline figures from the general elite survey reveals some important variation in legitimacy for ICANN by elite sector (Figure 2). For example, average confidence for ICANN from civil society (1.47) and political parties (1.62) comes lower than the overall elite score of 1.70, while averages for media (1.71), business (1.73), research (1.75), and government bureaucracy (1.78) come higher. More politicized elites therefore tend to give ICANN lower confidence than more technocratic circles.

Country variation in elite opinion toward ICANN is still greater (Figure 3). Average confidence for ICANN falls starkly below the overall mean among elites in the Philippines (1.27) and South Africa (1.29). It is somewhat lower in Germany (1.64) and well above the overall average in Brazil (1.86), Russia (1.91), and the United States (1.93). Countries with the lowest confidence 


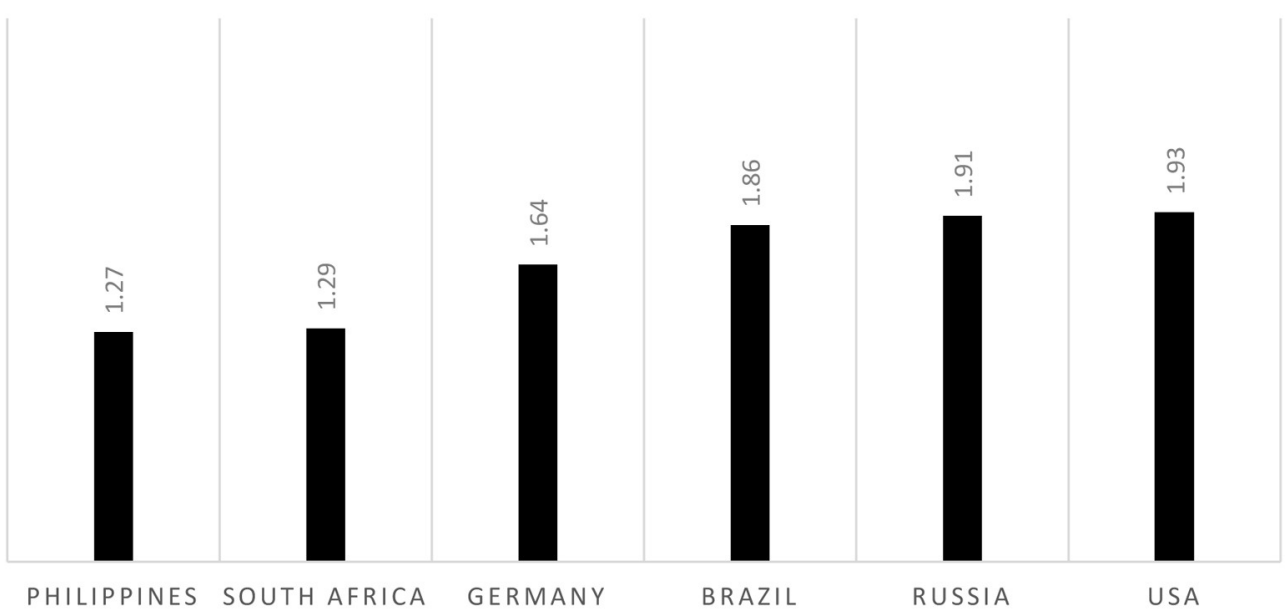

FIGURE 3 Confidence in the Internet Corporation for Assigned Names and Numbers (ICANN) across countries (elites; means, o- 3 scale; $N=367$ )

DATA FROM VERHAEGEN ET AL. (2O19)

scores also tend to have the highest percentages of "don't know/no response," thereby deepening their legitimacy deficit toward ICANN. The high rating from US elites is unsurprising, given their country's historical leading role at ICANN. Decidedly unexpected is the high score from Russia, given the Kremlin's long objections to ICANN, although the country also had a “don't know/no response" level of 56.5 percent.

In sum, ICANN's legitimacy cup with general elites is both half full and half empty. Optimistic readings can stress that ICANN holds its ground vis-à-vis multilateral bodies and comes ahead of two other surveyed multistakeholder institutions. As Figure 1 further shows, elite confidence in ICANN ranks more or less evenly with that toward national and regional governance. Yet pessimistic readings can emphasize that overall elite legitimacy beliefs for ICANN — and for governance institutions generally-are unimpressively middle range and that many elites are unfamiliar with ICANN. Decidedly high levels of confidence are missing.

\subsection{ICANN in Comparison with Other Internet Governance Institutions}

Our second step in data analysis considers the narrower circle of elites who occupy themselves specifically with internet regulation. Here, we asked ICANN insiders and informed outsiders about their confidence (now on a scale of $\mathrm{O}-4$ ) in the current workings of six sites of governance for the global internet. Three of the institutions (ICANN, IETF, and RIRs) are private multistakeholder arrangements that involve, at most, a consultative role for government. 
$\square$ Total insiders (weighted) $\mathbf{\nabla}$ ICANN board $\quad$ 口ICANN staff $\quad$ IICANN community $\quad$ Informed outsiders

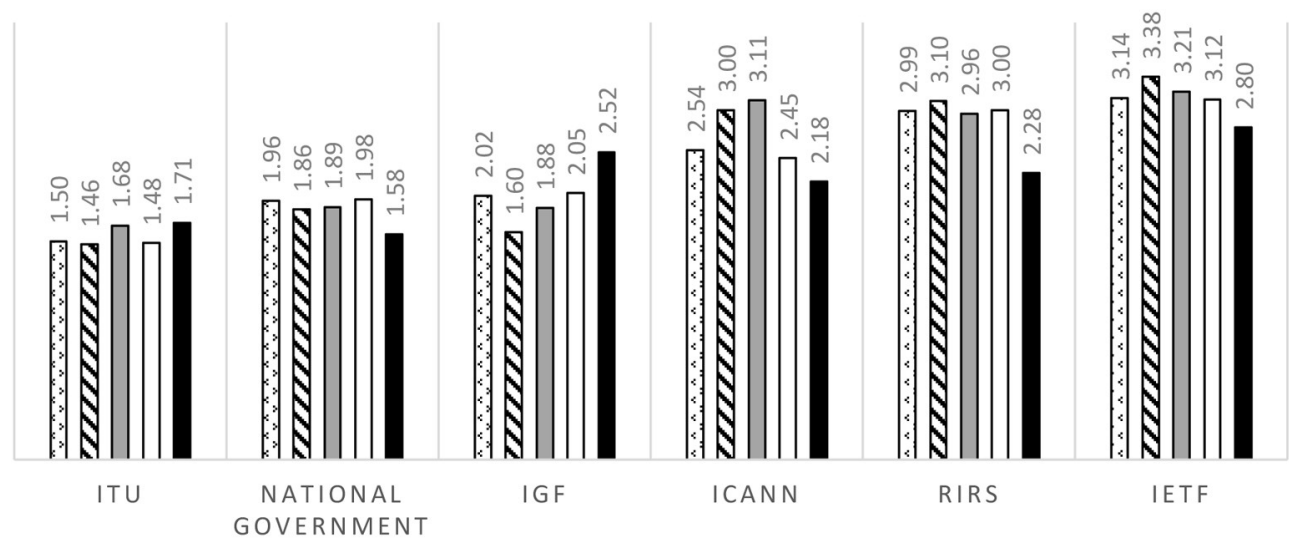

FIGURE 4 Confidence in various internet governance organizations (means, o-4 scale) Survey item: "Generally, when it comes to policy development about the Internet, how much confidence do you have in the current workings of [ICANN overall, the ITU, the IGF, the IETF, your RIR (AFRINIC, APNIC, ARIN, LACNIC, RIPE), your national government]?"

A fourth body, the IGF, is a multistakeholder framework under the UN and, thus, includes a greater role for states. The fifth agency, the ITU, is a multilateral institution. We also asked respondents to indicate their level of confidence in their national government's handling of internet policy.

As seen in Figure 4, ICANN insiders on average have notably high confidence in the IETF (3.14) and the RIRs (2.99). ICANN itself lands halfway between "moderate" and "high" confidence (2.54). The IGF, a multistakeholder initiative within the multilateral sphere, scores squarely at the "moderate confidence" level, with a mean of 2.02. National governments average broadly the same, at 1.96, while the intergovernmental ITU averages midway between "moderate" and "low" confidence, at 1.50. However, we should note that 28 percent of respondents felt insufficiently knowledgeable to judge the ITU, while around 16 percent disqualified themselves from assessing the IETF, RIRs, and IGF.

Informed outsiders to ICANN assess these organizations somewhat differently. Average confidence in the IETF (2.80), the RIRs (2.28), and ICANN (2.18) come in the same order, but at notably lower levels than for the ICANN insiders. In contrast, the informed outsider group has considerably higher confidence in the IGF (2.52), not surprising since these respondents were drawn from regular IGF participants. Meanwhile, compared to ICANN insiders, informed outsiders have slightly more confidence in the ITU (1.71) and rather less confidence in their national governments (1.58). 


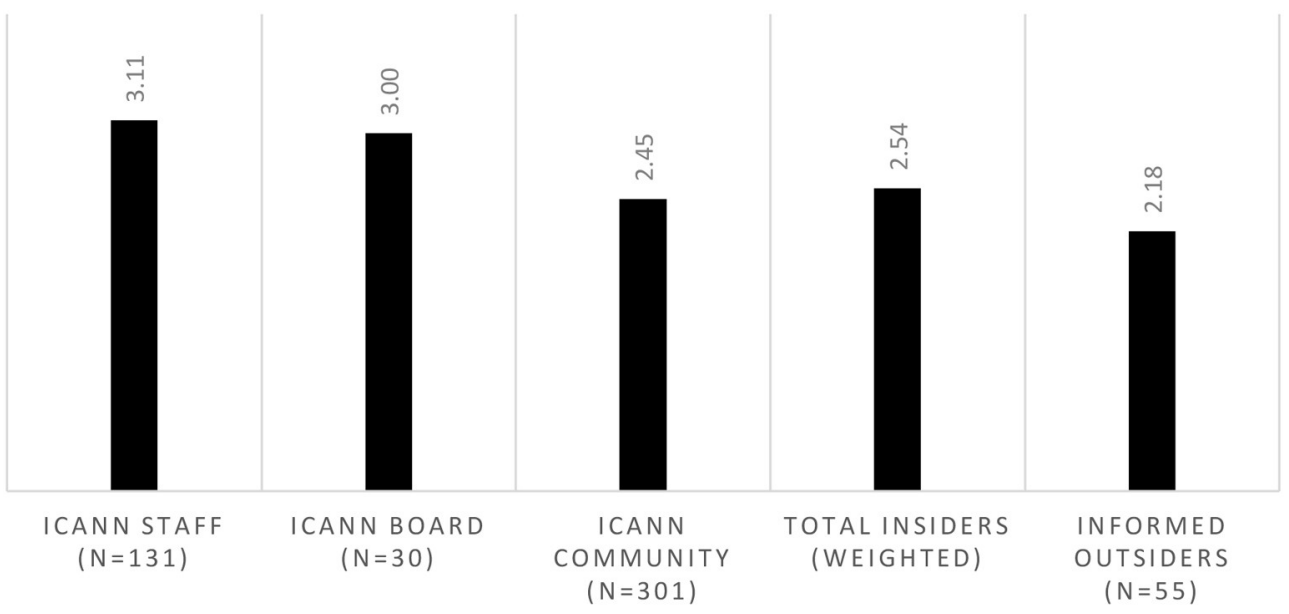

FIGURE 5 Confidence in the Internet Corporation for Assigned Names and Numbers (ICANN) overall (means, $\mathrm{O}-4$ scale; $N=517$ )

The striking pattern here sees an inverse relationship between level of legitimacy beliefs and level of state involvement. With no formal role for states, the IETF and RIRs attract the highest mean confidence. With a secondary role for states, ICANN and the IGF obtain the middle average scores. With a primary state orientation, the ITU and national governments receive the lowest assessments. Our sample therefore decidedly prefers multistakeholderism over statism.

\subsection{ICANN Legitimacy: Variation by Board, Community, Staff, and Informed Outsiders}

We now examine more closely the survey results for ICANN in particular, to assess variations in legitimacy perceptions between subpopulations. A first cut may distinguish between four groups: the board of directors, the staff ("ICANN org"), stakeholder participants ("the community"), and informed outsiders. Here we find that, as per Figure 5, mean scores for the board and staff show "high confidence", at 3.00 and 3.11, respectively. Legitimacy beliefs among community members, while still substantial, average at 2.45 , roughly halfway between "moderate" and "high" confidence. For informed outsiders, the mean of 2.18 drops closer to the "moderate" level. In sum, in line with our expectations, the strength of legitimacy beliefs toward ICANN tends to correlate with closeness to the heart of the regime. Although this finding might seem unsurprising at first, other studies have shown that staff of global institutions can also have more qualified confidence in their organization. ${ }^{31}$ 


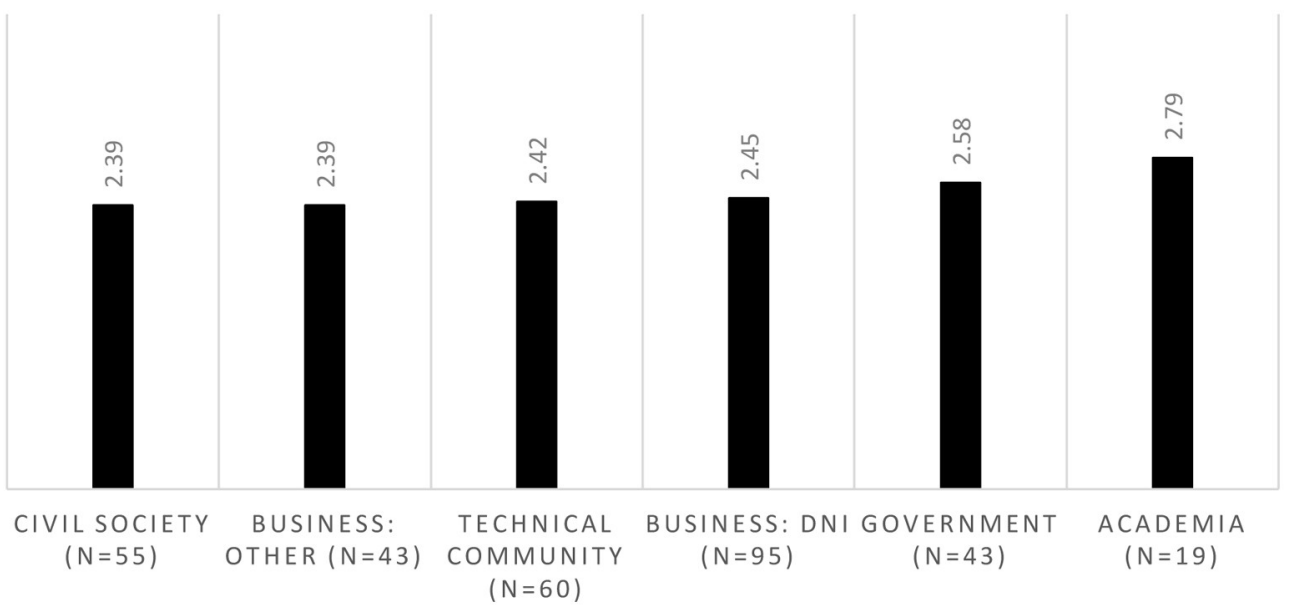

FIGURE 6 Confidence in the Internet Corporation for Assigned Names and Numbers (ICANN) according to stakeholder group (means; o-4 scale; $N=315$ )

Only ICANN insiders, weighted data.

Independent samples $t$-tests reveal that differences between the ICANN board and community are statistically significant $(t=3.335 ; p \leq 0.001)$, as are differences between the board and informed outsiders ( $t=4.546 ; p \leq 0.001)$. The same holds between ICANN staff and community $(t=7.964 ; p \leq 0.001)$ and between ICANN staff and informed outsiders $(t=7.561 ; p \leq 0.001)$. Finally, significant differences exist between the ICANN community and informed outsiders $(t=2.278 ; p \leq 0.05)$.

\subsection{ICANN Legitimacy: Variation by Stakeholder Sector}

Does similar consistency of legitimacy beliefs in ICANN hold across stakeholder sectors? We examine the views held by six stakeholder groups: Academia, Business: Domain Name Industry (registries and registrars), Business: Other (internet service providers, intellectual property, etc.), Civil Society, Government, and Technical Community. As ICANN staff members do not affiliate with any of these groups, we exclude them from the stakeholder analysis.

As seen in Figure 6, participants in ICANN from academia have the highest average confidence in the regime (2.79), followed by respondents from government (2.58). ICANN watchers might find this result somewhat surprising, given that these two constituencies often voice some of the sharpest critiques of ICANN policies. However, as noted earlier, legitimacy beliefs in a regime are distinct from - and run deeper than-views on particular decisions. In addition, ICANN staff have pursued intensive efforts over recent years to court governments. Four other stakeholder groups cluster around the 2.40 mark, with 
mean confidence scores for Business: Domain Name Industry at 2.45, the Technical Community at 2.42, and both Business: Other and Civil Society at 2.39.

On the whole, then, current legitimacy beliefs toward ICANN do not show much variation by stakeholder affiliation, and none of these differences is statistically significant. ${ }^{32}$ Moreover, academia as the main outlier is a relatively small constituency in global internet governance. For the rest, confidence levels are consistently solid (though more toward "moderate" than "high") across business, civil society, government, and technical circles. Notably, civil society delivers the lowest sectoral score in both the ICANN survey and the general elite survey, which tends to confirm conceptions of civil society as a critical watchdog for global governance. ${ }^{33}$

Hence, most of the stakeholder populations give ICANN a verdict of "room for improvement." The observed lack of variation in legitimacy perceptions across stakeholder groups is surprising. We could expect the business sector with its strong position to hold higher legitimacy beliefs toward ICANN; however, if anything the opposite prevails. Also surprising is the relatively high score from government circles - ahead of business and technical groups-in spite of the secondary role of states at ICANN. In this case, level of confidence does not correlate with degree of influence.

\subsection{ICANN Legitimacy: Variation by Geographical Region}

Next, we disaggregate the ICANN insider data on geographical lines. The regional comparison yields somewhat greater variation than the stakeholder comparison (Figure 7). The mean scores lean more toward the "high" rating in the cases of East, Southeast and South Asia (2.83), Sub-Saharan Africa (2.72), and Latin America and Caribbean (2.69). The means fall toward the midpoint between "moderate" and "high" confidence in the cases of Oceania (2.6o), North America (2.51), Middle East and North Africa (2.46), and Europe (2.42). Only the average for Russia and Central Asia dips to the "moderate" level (2.05), although the evidence base from this region is small, which reflects low participation in ICANN from these countries. Statistically significant differences exist: (a) between respondents from Russia/Central Asia and all other groups; and (b) between East, South, and Southeast Asian respondents and European respondents (Table 1).

32 Only the difference between academia and business (DNI) is statistically significant $(t=$ 2.044; $p \leq 0.05$ ), but this significance falls away using unweighted data as well as when using Mann-Whitney U.

Scholte 2011. 


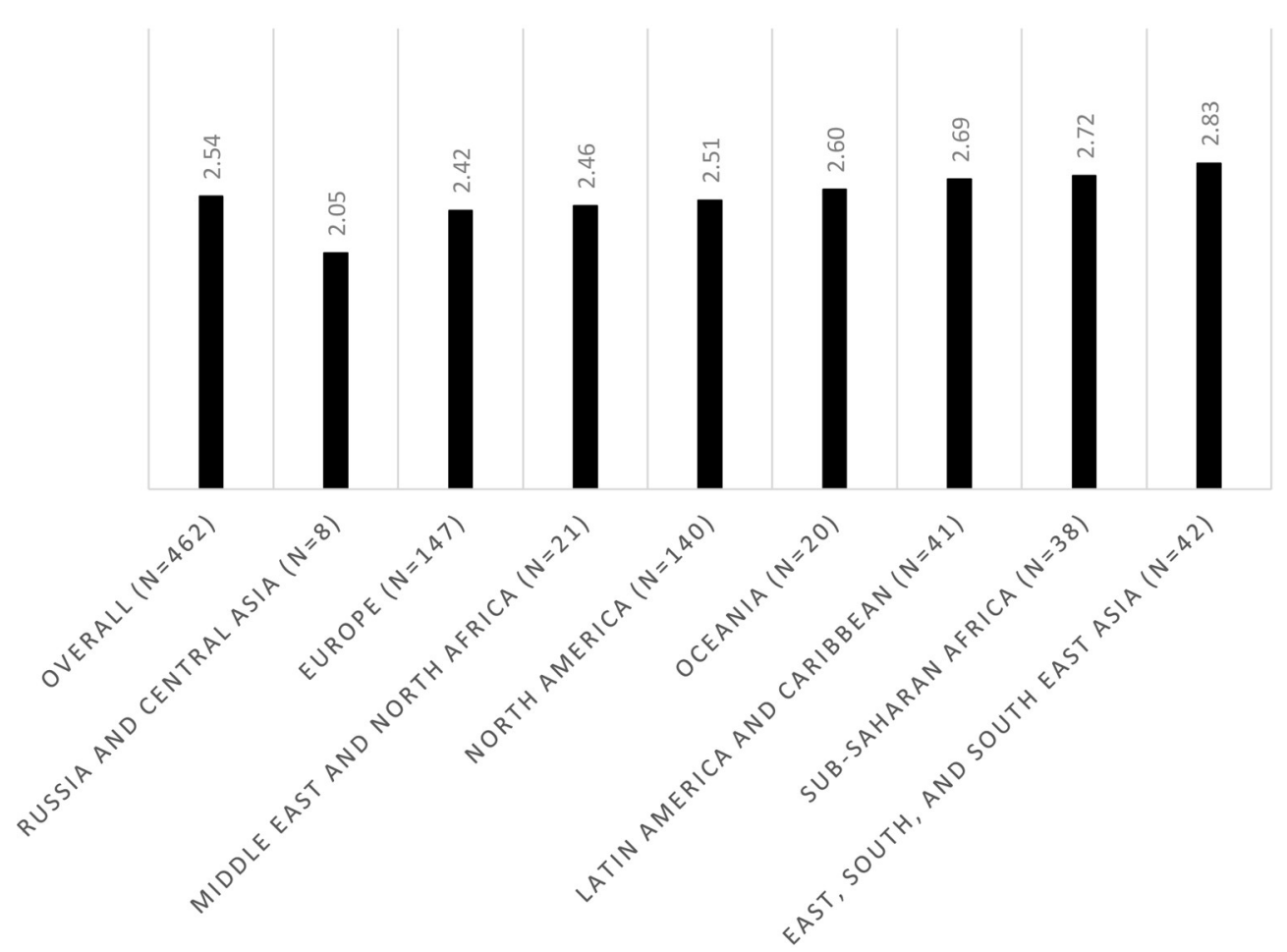

FIGURE 7 Confidence in the Internet Corporation for Assigned Names and Numbers (ICANN) according to region (means; $\mathrm{O}-4$ scale; $N=457$ )

Only ICANN insiders, weighted data.

Noteworthy in the regional data is the absence of a so-called North-South divide. If anything, and against our expectations, respondents from Global South regions (i.e., low- and middle-income countries) express somewhat higher average confidence in ICANN than respondents from the Global North (i.e., high-income countries). Even though participants from Europe and North America form a large majority at ICANN meetings, with potentially greater influence, they do not report stronger confidence in ICANN. Like the stakeholder group comparison, the regional comparison suggests a lack of correlation between level of influence and level of legitimacy beliefs. Possibly this prima facie counterintuitive result could reflect the intensified efforts at so-called global stakeholder engagement that ICANN has undertaken since 2012, devoting substantial resources to supporting participation from so-called underrepresented regions. Recall from Figure 3 that general elites from Global South countries such as the Philippines and South Africa-so individuals not courted by ICANN—had strikingly low confidence in this regime. 
TABLE 1 Confidence in the Internet Corporation for Assigned Names and Numbers (ICANN) overall: Independent samples $t$-test (o-4 scale; $N=457$ )

\begin{tabular}{|c|c|c|c|c|c|c|c|c|}
\hline & $\begin{array}{l}\text { Means } \\
(S D)\end{array}$ & $\begin{array}{l}t \text {-value: } \\
\text { Europe }\end{array}$ & $\begin{array}{c}t \text {-value: } \\
\text { Latin } \\
\text { America } \\
\text { and Caribb. }\end{array}$ & $\begin{array}{c}t \text {-value: } \\
\text { Middle East } \\
\text { and } \\
\text { North Africa }\end{array}$ & $\begin{array}{c}t \text {-value: } \\
\text { North } \\
\text { America }\end{array}$ & $\begin{array}{l}t \text {-value: } \\
\text { Oceania }\end{array}$ & $\begin{array}{c}t \text {-value: } \\
\text { Sub- } \\
\text { Saharan } \\
\text { Africa }\end{array}$ & $\begin{array}{c}t \text {-value: } \\
\text { Russia and } \\
\text { Central } \\
\text { Asia }\end{array}$ \\
\hline $\begin{array}{l}\text { East, South, } \\
\text { Southeast Asia }\end{array}$ & $2.83(0.73)$ & $3.083^{* *}$ & 0.742 & 1.845 & $2.357^{*}$ & 1.185 & o.693 & $5.681^{* * *}$ \\
\hline Europe & $2.42(0.93)$ & - & -1.637 & -0.188 & -0.815 & -0.894 & -1.954 & $3 \cdot 349^{* * *}$ \\
\hline $\begin{array}{l}\text { Latin America } \\
\text { and Caribbean }\end{array}$ & $2.69(1.07)$ & - & - & 0.847 & 1.084 & 0.326 & -0.162 & $3.5^{2} 5^{* * *}$ \\
\hline $\begin{array}{l}\text { Middle East } \\
\text { and North } \\
\text { Africa }\end{array}$ & $2.46(0.76)$ & - & - & - & -0.229 & -0.618 & -1.226 & $2.135^{*}$ \\
\hline North America & $2.5^{1}(0.89)$ & - & - & - & - & -0.475 & $-1.39^{\circ}$ & $4.027^{* * *}$ \\
\hline Oceania & $2.60(0.74)$ & - & - & - & - & - & -0.571 & $3.109^{* *}$ \\
\hline $\begin{array}{l}\text { Sub-Saharan } \\
\text { Africa }\end{array}$ & $2.72(0.97)$ & - & - & - & - & - & - & $4.660^{* * * *}$ \\
\hline $\begin{array}{l}\text { Russia and } \\
\text { Central Asia }\end{array}$ & $2.05(0.24)$ & - & - & - & - & - & - & - \\
\hline
\end{tabular}

${ }^{*} p \leq 0.05,{ }^{* *} p \leq 0.01,{ }^{* * *} p \leq 0.001$; only ICANN insiders, weighted data.

\subsection{ICANN Legitimacy: Variation by Social Group}

A similar absence of relationship between levels of participation in ICANN and perceptions of legitimacy in ICANN appears with respect to social categories such as gender, age, language, and ethnicity/race. Here, too, the evidence reveals only modest differences, which goes against our starting expectations that groups which are generally perceived as subordinated would accord ICANN lower legitimacy. Again, these relatively high confidence levels among subordinated groups might indicate that ICANN's efforts to include women and younger-aged participants, as well as its large language services program, have borne fruit.

The smallest differences by social category appear in relation to gender. For ICANN insiders, the mean scores are 2.48 for female respondents and 2.57 for male respondents, so in both cases solidly halfway between "high" and "moderate" confidence. The difference is negligible and not statistically significant.

As for age, everyday conversation around ICANN often brings complaints that the regime is dominated by old-timers and needs fresh blood from the next generation. Yet, as with regional and gender data, unequal participation on lines of age does not translate into substantially lower legitimacy beliefs (Figure 8). True, among ICANN insiders, the mean confidence for respondents 


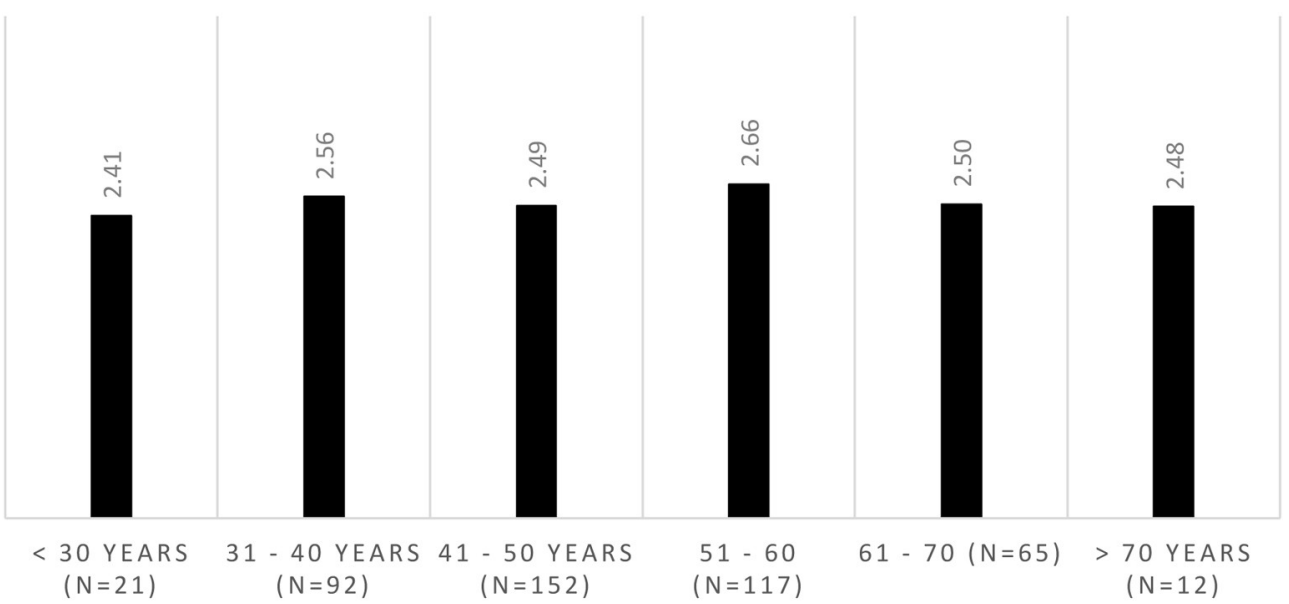

FIGURE 8 Confidence in the Internet Corporation for Assigned Names and Numbers (ICANN) according to age (means; $\mathrm{O}-4$ scale; $N=459$ ) Only ICANN insiders, weighted data.

30 years and younger is the lowest (2.41), while the mean for the $5^{1-60}$ age group is the highest (2.66). On the other hand, the next highest average score lies with the 31-40 age group (2.56), while the next lowest score lies with the middle-aged 41-50 group (2.49). In any case, the gap between highest and lowest average by age is small, and all are close to the midpoint between "moderate" and "high" confidence.

Shifting attention to language, do legitimacy beliefs toward ICANN vary in accordance with competence in English, the regime's main working language? We asked respondents to indicate their competence in English. As Figure 9 indicates, all three language categories report average confidence levels around the midpoint between "moderate" and "high." Moreover, confidence does not increase with greater English competence. On the contrary, among the ICANN insiders, the English native speakers express the lowest average confidence (2.43), while those with strong non-native English skills return the highest mean (2.69). Respondents with lower English skills fall in between (2.52). In short, legitimacy perceptions vis-à-vis ICANN show little variation by level of English.

What about variation in legitimacy beliefs according to ethnic/racial affiliation? During pre-project interviews, several respondents pointedly described circumstances in which they perceived that color shaped their involvement in ICANN in troubling ways. We therefore decided to probe these issues in the survey, although several respondents objected to raising the question of ethnicity/race. As seen in Figure 10, mean confidence in ICANN by ethnic/racial 


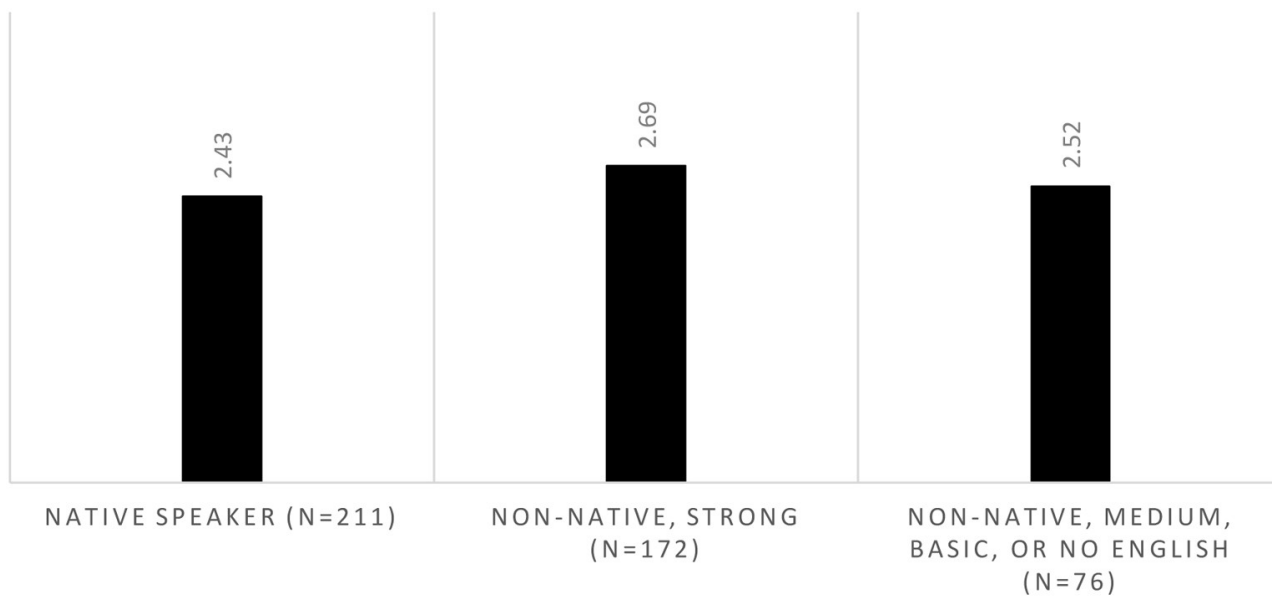

FIGURE 9 Confidence in the Internet Corporation for Assigned Names and Numbers (ICANN) according to (self-assessed) English language skills (means; o-4 scale; $N=459$ )

Only ICANN insiders, weighted data.

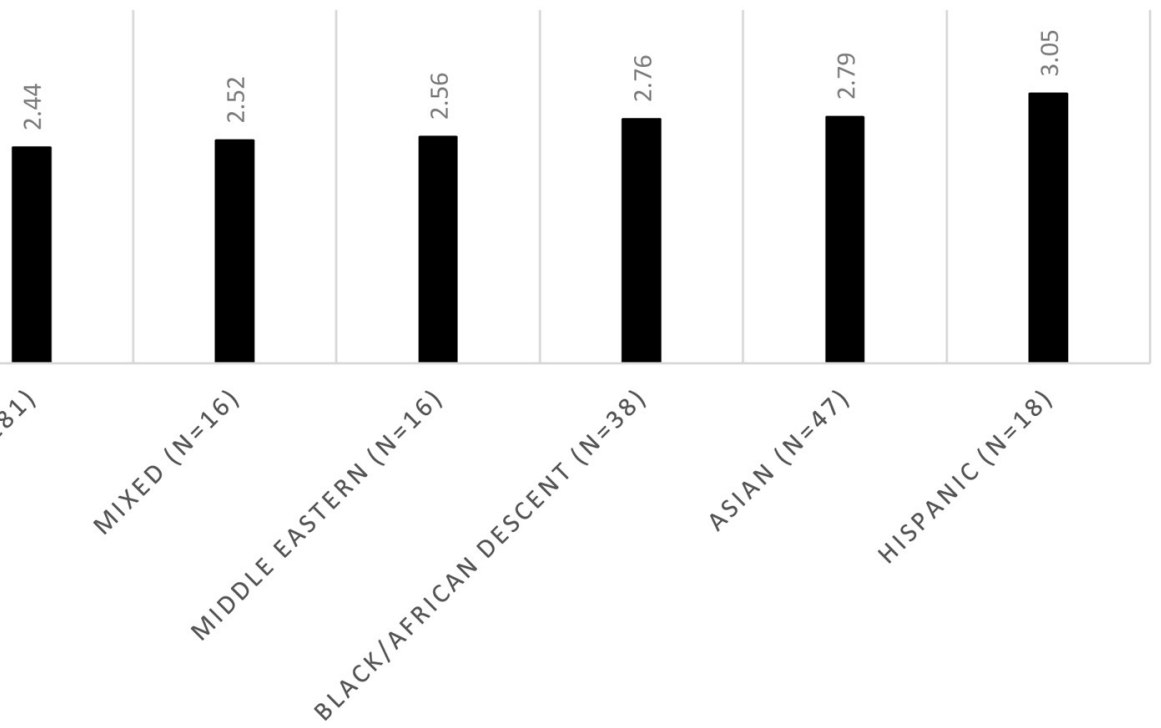

FIGURE 10 Confidence in the Internet Corporation for Assigned Names and Numbers (ICANN) by ethnic/racial self-identification (means; o-4 scale; $N=416$ )

Only ICANN insiders, weighted data. 
self-identification shows the largest variation among the four social groupings investigated. This spread is also larger than variations by stakeholder sector and world region. Yet the direction of those differences does not correlate with levels of participation at ICANN. Respondents who identify as white express the lowest mean confidence (2.44), followed by mixed ethnicity/race $\left(2.5^{2}\right)$ and Middle Eastern (2.56). The higher mean confidences are reported by respondents who identify as black and African descent (2.76), Asian (2.79), and Hispanic (3.05). Differences are statistically significant between white respondents, on the one hand, and respondents who identify as Asian $(t=-2.480 ; p \leq$ $0.05)$, black or African descent $(t=-2.258 ; p \leq 0.05)$, and Hispanic $(t=-2.504$; $p \leq 0.05)$, on the other. Reasons for these divergences by ethnicity/race are not evident, although they seem largely to coincide with regional differences.

In sum, among ICANN insiders, legitimacy beliefs toward this global multistakeholder regime are quite solid across all social groups. Likewise, most of the stakeholder and regional averages fall in the band between 2.4 and 2.8. Hence, patterns of ICANN legitimacy among regime insiders show neither strikingly weak spots nor strikingly strong points.

\section{$5 \quad$ Conclusion}

This article has explored levels and patterns of legitimacy beliefs with respect to multistakeholder global governance at ICANN. From a large and systematic evidence base, we have found that ICANN has strong legitimacy underpinnings among its staff and board, as well as quite uniformly moderate-to-high legitimacy among its "community." Notably—and in some cases somewhat surprisingly — these legitimacy beliefs for ICANN hold quite steady across stakeholder groups, geographical regions, and social categories. However, average levels of legitimacy perceptions tend to decline the more one moves away from ICANN's immediate sphere into wider internet governance. Moreover, in society at large, half of elites and most of the public remain ignorant of ICANN, so the regime's legitimacy base is quite narrow. In sum, ICANN's current legitimacy position is fairly secure on the inside and somewhat more wobbly on the outside.

To reiterate an earlier caveat, this article has not probed beyond interpretations of descriptive data to inquire into the drivers of these levels and patterns of legitimacy beliefs. We have a theoretical framework for such explanatory analysis, ${ }^{34}$ and our surveys also include questions that provide us with rich

Tallberg, Bäckstrand, and Scholte 2018; Scholte 2019. 
data to test various causal propositions. Such an explanatory analysis might also offer new insights into the relationship between normative and sociological understandings of legitimacy; notably, the extent to which prevailing social norms impact on legitimacy beliefs toward ICANN. Explanatory analysis can also point toward the kinds of reforms that ICANN and other multistakeholder bodies could consider in order further to enhance their legitimacy in contemporary global governance. However, these additional inquiries lie in the future.

Returning to the present article, what might its analysis of levels and patterns of confidence toward ICANN suggest about legitimacy beliefs in multistakeholder global governance more generally? We best exercise caution about drawing larger conclusions at this stage. After all, while ICANN is a prominent example of the multistakeholder genre, it is but one case. Indeed, the general elite survey shows that two other global multistakeholder initiatives-in particular, the Kimberley Process - attracted lower average legitimacy beliefs than ICANN. Detailed comparative research into these and other regimes would be required before we could begin to hazard bigger claims about legitimacy vis-à-vis multistakeholder arrangements in current and future global governance.

In the meantime, it may be more suitable to treat ICANN as a special case. ICANN's experience shows what extent of legitimacy a global multistakeholder arrangement can realize in the early twenty-first century, particularly if it undertakes sustained intensive efforts to build support. Maybe, in longer historical perspective, ICANN will come to be seen as a pioneer in the legitimation of a new kind of global governance. Or not. Stay tuned.

\section{Bibliography}

Abbott, Kenneth W., and Duncan Snidal. "The Governance Triangle: Regulatory Standards Institutions and the Shadow of the State." In The Politics of Global Regulation, eds. Walter Mattli and Ngaire Woods (Princeton: Princeton University Press, 2009), 44-88.

Antonova, Slavka. Powerscape of Internet Governance: How Was Global Multistakeholderism Invented in ICANN? (Saarbrücken: VDM, 2008).

Barker, Rodney. Political Legitimacy and the State (Oxford: Oxford University Press, 1990).

Becker, Manuel. "When Public Principals Give up Control over Private Agents: The New Independence of ICANN in Internet Governance." Regulation \& Governance 13 (4) (2019), 561-576.

Beetham, David. The Legitimation of Power (Basingstoke: Palgrave Macmillan, 2013). 
Bernstein, Steven. "Legitimacy in Intergovernmental and Non-State Global Governance." Review of International Political Economy 18 (1) (2011), 17-51.

Bernstein, Steven, and Benjamin Cashore. "Can Non-State Global Governance Be Legitimate? An Analytical Framework." Regulation \& Governance 1 (4) (2007), 347-371.

Bexell, Magdalena, and Kristina Jönsson. "Audiences of (De)Legitimation in Global Governance." In Legitimacy in Global Governance: Sources, Processes, and Consequences, eds. Jonas Tallberg, Karin Bäckstrand and Jan Aart Scholte (Oxford: Oxford University Press, 2018), 119-133.

Black, Julia. "Constructing and Contesting Legitimacy and Accountability in Polycentric Regulatory Regimes." Regulation \& Governance 2 (2) (2008), 137-164.

Cashore, Benjamin. "Legitimacy and Privatization of Environmental Governance: How Non-State Market-Driven (NSMD) Governance Systems Gain Rule-Making Authority." Governance 15 (4) (2002), 503-530.

Curtin, Deidre, and Linda Senden. "Public Accountability of Transnational Private Regulation: Chimera or Reality?" Journal of Law and Society 38 (1) (2011), 163-188.

Dellmuth, Lisa M., Jan Aart Scholte, and Jonas Tallberg. "Institutional Sources of Legitimacy for International Organizations: Beyond Procedure versus Performance." Review of International Studies 47 (4) (2019), 627-646.

Dellmuth, Lisa M., and Jonas Tallberg. "The Social Legitimacy of International Organisations: Interest Representation, Institutional Performance, and Confidence Extrapolation in the United Nations." Review of International Studies 41 (3) (2015), 451-475.

Dingwerth, Klaus. The New Transnationalism: Transnational Governance and Democratic Legitimacy (Basingstoke: Palgrave Macmillan, 2007).

Dingwerth, Klaus, Antonia Witt, Ina Lehmann, Ellen Reichel, and Tobias Weise. International Organizations under Pressure: Legitimating Global Governance in Challenging Times (Oxford: Oxford University Press, 2019).

Easton, David. "A Re-Assessment of the Concept of Political Support." British Journal of Political Science 5 (4) (1975), 435-457.

Ecker-Ehrhardt, Matthias. "Why Do Citizens Want the UN to Decide? Cosmopolitan Ideas, Particularism and Global Authority." International Political Science Review 37 (1) (2016), 99-114.

Flyverbom, Mikkel. The Power of Networks: Organizing the Global Politics of the Internet (Cheltenham: Edward Elgar, 2011).

Gleckman, Harris. Multistakeholder Governance and Democracy: A Global Challenge (Abingdon: Routledge, 2018).

Habermas, Jürgen. Legitimation Crisis (London: Heinemann, [1973] 1976).

Hahn, Rüdiger, and Christian Weidtmann. "Transnational Governance, Deliberative Democracy, and the Legitimacy of ISO 2600o: Analyzing the Case of a Global Multistakeholder Process." Business and Society 55 (1) (2016), 90-129.

Hallström, Karin Tamm, and Magnus Boström. Transnational Multi-Stakeholder Stan- 
dardization: Organizing Fragile Non-State Authority (Cheltenham: Edward Elgar, 2010).

Hofmann, Jeanette. "Multi-Stakeholderism in Internet Governance: Putting a Fiction into Practice." Journal of Cyber Policy 1 (1) (2016), 29-49.

Hopgood, Stephen. Keepers of the Flame: Understanding Amnesty International (Ithaca: Cornell University Press, 2006).

Jongen, Hortense and Jan Aart Scholte. "Sampling Procedure and Interview Process of the ICANN Survey. Online Annex for the article 'Legitimacy in Multistakeholder Global Governance at ICANN.'” Website of Hortense Jongen: https://files.hortense jongen.com/Legitimacy_in_ICANN_Annex.pdf

Khagram, Sanjeev. "Possible Future Architectures of Global Governance: A Transnational Perspective/Prospective." Global Governance 12 (1) (2006), 97-117.

Kleinwächter, Wolfgang. "Beyond ICANN vs ITU? How WSIS Tries to Enter the New Territory of Internet Governance." Gazette 66 (3-4) (2004), 233-251.

Koppell, Jonathan G.S. "Pathologies of Accountability: ICANN and the Challenge of 'Multiple Accountabilities Disorder'” Public Administration Review 65 (1) (2005), 92108.

Kurbalija, Jovan, and Valentin Katrandjiev, eds. Multistakeholder Diplomacy: Challenges and Opportunities (Geneva: DiploFoundation, 2006).

Mackenzie, Tom, Nick Thorne, Timothy McGinnis, and Rosa Delgado. Review of the ICANN At-Large Community Final Report (Paris: ITEMS International, 2017).

Mahler, Tobias. Generic Top-Level Domains: A Study of Transnational Private Regulation (Cheltenham: Edward Elgar, 2019).

Marx, Axel. "Legitimacy, Institutional Design, and Dispute Settlement: The Case of EcoCertification Systems." Globalizations 11 (3) (2014), 401-416.

Mayntz, Renate. "Legitimacy and Compliance in Transnational Governance." Working Paper 10/5 (Cologne: Max-Planck-Institut für Gesellschaftsforschung, 2010).

Mounier, Pierre. "Internet Governance and the Question of Legitimacy." In Governance, Regulations and Powers on the Internet, eds. Eric Brousseau, Meryem Marzouki, and Cécile Méadel (Cambridge: Cambridge University Press, 2012), 170-185.

Mueller, Milton. Networks and States: The Global Politics of Internet Governance (Cambridge, MA: MIT Press, 2010).

Nasiritousi, Nagmeh, and Soetkin Verhaegen. "Disentangling Legitimacy: Comparing Stakeholder Assessments of Five Key Climate and Energy Governance Institutions." In Governing the Climate-Energy Nexus: Challenges to Coherence, Legitimacy, and Effectiveness, eds. Fariborz Zelli, Karin Bäckstrand, Nagmeh Nasiritousi, Jakob Skovgaard, and Oskar Widerberg (Cambridge: Cambridge University Press, 2020), 183-211

Norris, Pippa. "Confidence in the United Nations: Cosmopolitan and Nationalistic Attitudes." In The International System, Democracy, and Values, eds. Yilmaz Esmer and Thorleif Pettersson (Uppsala: Acta Universitatis Upsaliensis, 20o9), 17-48. 
Ottaway, Marina. "Corporatism Goes Global: International Organizations, Nongovernmental Organization Networks, and Transnational Business." Global Governance 7 (3) (2001), 265-292.

Palfrey, John G. “The End of the Experiment: How ICANN'S Foray into Global Internet Democracy Failed." Harvard Journal of Law and Technology 17 (2) (2004), 409-473.

Parsons, Talcott. Structure and Process in Modern Societies (Glencoe, IL: Free Press, 1960).

Quack, Sigrid. "Law, Expertise and Legitimacy in Transnational Economic Governance: An Introduction." Socio-Economic Review 8 (1) (2010), 3-16.

Raymond, Mark, and Laura DeNardis. "Multistakeholderism: Anatomy of an Inchoate Global Institution." International Theory 7 (3) (2015), 572-616.

Scholte, Jan Aart, ed. Building Global Democracy? Civil Society and Accountable Global Governance (Cambridge: Cambridge University Press, 2011).

Scholte, Jan Aart. "Sources of Legitimacy in Global Governance." Outlines of Global Transformations: Politics, Economics, Law 12 (3) (2019), 47-76.

Sommerer, Thomas, and Hans Agné. "Consequences of Legitimacy in Global Governance." In Legitimacy in Global Governance: Sources, Processes, and Consequences, eds. Jonas Tallberg, Karin Bäckstrand and Jan Aart Scholte (Oxford: Oxford University Press, 2018), 153-168.

Strickling, Lawrence. Public remarks of the US Assistant Secretary of State at the Internet Governance Forum, Guadalajara, December 2016.

Suchman, Marc C. "Managing Legitimacy: Strategic and Institutional Approaches." Academy of Management Review 20 (3) (1995), 571-610.

Take, Ingo. "Regulating the Internet Infrastructure: A Comparative Appraisal of the Legitimacy of ICANN, ITU, and the WSIS." Regulation \& Governance 6 (4) (2012), 499-523.

Tallberg, Jonas, Karin Bäckstrand, and Jan Aart Scholte, eds. Legitimacy in Global Governance: Sources, Processes, and Consequences (Oxford: Oxford University Press, 2018).

Tapscott, Don. "Introducing Global Solution Networks: Understanding the New MultiStakeholder Models for Global Cooperation." Problem Solving and Governance Innovations 9 (1-2) (2014), 3-46.

Verhaegen, Soetkin, Lisa Maria Dellmuth, Jan Aart Scholte, and Jonas Tallberg. "Legitimacy in Global Governance (LegGov) Elite Survey: Technical Report." 2019. Website of the Legitimacy in Global Governance Program, https://www.statsvet.su.se/ leggov/leggov-elite-survey/leggov-elite-survey-1.447763.

Voeten, Erik. "Public Opinion and the Legitimacy of International Courts." Theoretical Inquiries in Law 14 (2) (2013), 411-436.

Waddell, Steve. Global Action Networks: Creating Our Future Together (Basingstoke: Palgrave, 2011).

Weber, Max. Economy and Society (Berkeley: University of California Press [1922] 1978). 
Weinberg, Jonathan. "ICANN and the Problem of Legitimacy." Duke Law Journal 50 (1) (2000), 187-26o.

Wigley, Barb. “The State of UNHCR's Organization Culture.” Report No. EPAU/2005/o8. (United Nations High Commissioner for Refugees Evaluation and Policy Analysis Unit, 2005). Available at: https://www.unhcr.org/428db1d62.pdf.

Zaum, Dominik, ed. Legitimating International Organizations (Oxford: Oxford University Press, 2013).

Zürn, Michael. A Theory of Global Governance (Oxford: Oxford University Press, 2018). 